\title{
A new phenomenon: the transient metastable graphitization of alloyed white iron
}

\author{
G I SILMAN* and A A ZHUKOV** \\ * Materials Science at the Briansk Institute of Technology, 241000, Russia \\ ** Machine-Building Technology at the Vinnitsa Technical University, 286021, Ukraine
}

MS received 28 September 1994

\begin{abstract}
In previous papers the case of stable-mottled irons has been analyzed. Hereunder a different case is looked into, when the mottled structure is a transient metastable state. Then the sequence of transformations during isothermal graphitizing annealing of some alloyed white irons can be summed up as follows:

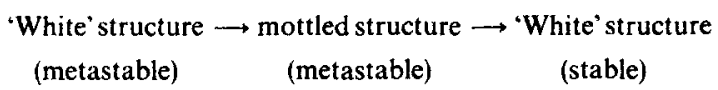

In the transient mottled state the alloys have a much lower hardness and can be machined before the final heat treatment.

A simplified theoretical approach to this phenomenon is being offered.
\end{abstract}

Keywords. Cementite; graphite; stable states; metastable states; non-equilibrium crystallization.

\section{Introduction}

Alloyed white cast irons can have metastable white and mottled structures which transform to the more stable white structure. Such a transition is possible for the simple reason that alloyed white iron is chemically inhomogeneous because of nonequilibrium crystallization. Then in certain parts of the alloy we will have a predominance of carbide-stabilizing elements (of the $\mathrm{Cr}$ type) and here the initial 'white' state of the alloy will be a stable one. In other parts of the alloy there will be a predominance of graphitizing elements (of the Si type) and then the initial state of the alloy will be a metastable one. Because of low diffusivity of the mentioned elements (especially $\mathrm{Cr}$ ) at temperatures of the solid state a short graphitizing anneal may provoke a partial graphitization in the second type of local microvolumes, while at long annealing times the system may become homogenized and will return to the 'white' state, but this time thermodynamically stable.

To such a qualitative explanation we can add the following theoretical approach, using 'geometrical' thermodynamics (Zhukov 1971, 1979; Silman et al 1983, 1986a).

\section{Theory}

Let us consider a simpler case of a ternary $\mathrm{Fe}-\mathrm{C}-\mathrm{Cr}$ system (figure 1). When the $\mathrm{Cr}$-content is low these alloys may initially have a metastable austenite (A) + cementite $(C)$ structure (chilled iron) at supercritical temperature $\left(>A_{1}\right)$, but after graphitizing annealing, the stable structure is austenite $(A)+$ graphite $(G)$. In figure 1 these alloys pertain to zone $A+G$. 


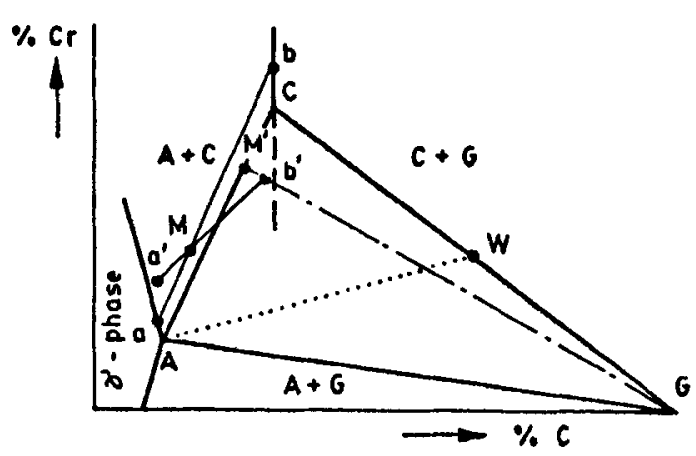

Figure 1. An isothermal section of the $\mathrm{Fe}-\mathrm{C}-\mathrm{Cr}$ phase diagram at a temperature under the solidus (schemat).

High-Cr alloys cannot graphitize and if austenite is still the high-temperature state of the solid $(\mathrm{Fe}, \mathrm{Cr})+\langle\mathrm{C}\rangle$ solution, they pertain to zone $\mathrm{A}+\mathrm{C}$ on the left side of figure 1 .

An intermediate state is described in figure 1 by the $A+G+C$ tie-line triangle inside which we have the corresponding three-phase equilibrium. Here graphitization of an initially chilled alloy can proceed only to a certain extent. Along the $A+C$ side of this triangle this extent is equal to zero, along the $A+G$ side it is equal to $100 \%$ and along the median $\mathrm{AW}$ it is $50 \%$. The mechanism of partial graphitization in the latter case is very simple. During the first stages of such a process part of the Cralloyed cementite is transformed into austenite. The partition ratio $\left\langle\mathrm{Cr}_{\mathrm{C}}\right\rangle /\left\langle\mathrm{Cr}_{\mathrm{A}}\right\rangle$ is larger than 1.0 (because the $A+C$ tie-lines have a positive slope in figure 1 and chromium is accumulated in the carbide phase). Therefore more $\langle\mathrm{Cr}\rangle$ is transferred by diffusion into the latter until it is fully stabilized by this additional portion of chromium. So graphitization stops at $50 \%$ if the alloys' descriptive points lie along the AW median.

This theory does not take into account kinetic circumstances. The latter inevitably appear because the diffusivity of $\mathrm{Cr}$ and $\mathrm{Fe}$ atoms is much smaller than that of $\mathrm{C}$ atoms. It has been shown in earlier works that in the $\mathrm{Fe}-\mathrm{C}-\mathrm{Cr}$ system the equilibrium partition coefficient $\left\langle\mathrm{Cr}_{\mathrm{C}}\right\rangle /\left\langle\mathrm{Cr}_{\mathrm{A}}\right\rangle$ in as-cast alloys rarely attains $70-80 \%$ of the equilibrium value (Silman et al 1983, 1986a). Then the following phenomenon takes place.

Let us suppose that in figure 1 alloy $M$ is situated in the $A+C$ zone and therefore pertains to a totally stable carbidic system austenite ' $a$ ' + cementite ' $b$ ' (see tie-line $\mathrm{ab}$ drawn in figure 1 slightly to the left side of the AC tie-line of the AGC tie-line triangle). Now let us suppose that due to kinetic circumstances the partition of $\mathrm{Cr}$ between phases has not been fully attained (see tie-line $a^{\prime} b^{\prime}$ in figure 1 drawn through point $M$ with a smaller slope). Then point $\mathrm{b}^{\prime}$ finds itself inside the AGC triangle and carbide $b^{\prime}$ is able to partly graphitize (the ratio between graphitized and ungraphitized zones may reach a maximum of $M^{\prime} C / A C$ ).

This partly graphitized state is a transient one. It can subsist only until the $b^{\prime}$ carbide phase remains impoverished in chromium. 


\section{Experimental}

The chemical composition of the investigated alloys is given in table 1 . Specimens with a $10 \mathrm{~mm}$ dia were cast into green sand moulds and in steel gravity die-moulds. In all cases the metal was chilled and there was no graphite in its microstructure.

The specimens were then subjected to graphitizing annealing in vacuum at $1050^{\circ} \mathrm{C}$. Influence of annealing time on the $R_{c}$ hardness of alloys (after cooling in air of the evacuated and sealed silica-glass ampoules) is shown in figure 2.

Table 1. Chemical composition of alloys.

\begin{tabular}{lcccc}
\hline & \multicolumn{4}{c}{ Content of elements (wt.\%) } \\
\cline { 2 - 5 } $\begin{array}{l}\text { No. of } \\
\text { alloys }\end{array}$ & $\mathrm{C}$ & $\mathrm{Si}$ & $\mathrm{Cr}$ & $\mathrm{Mn}$ \\
\hline 1 & 3.19 & 1.86 & 1.86 & 0.72 \\
2 & 3.29 & 1.85 & 2.11 & 0.72 \\
3 & 3.38 & 1.93 & 2.58 & 0.93 \\
4 & 3.38 & 2.07 & 2.90 & 1.03 \\
\hline
\end{tabular}
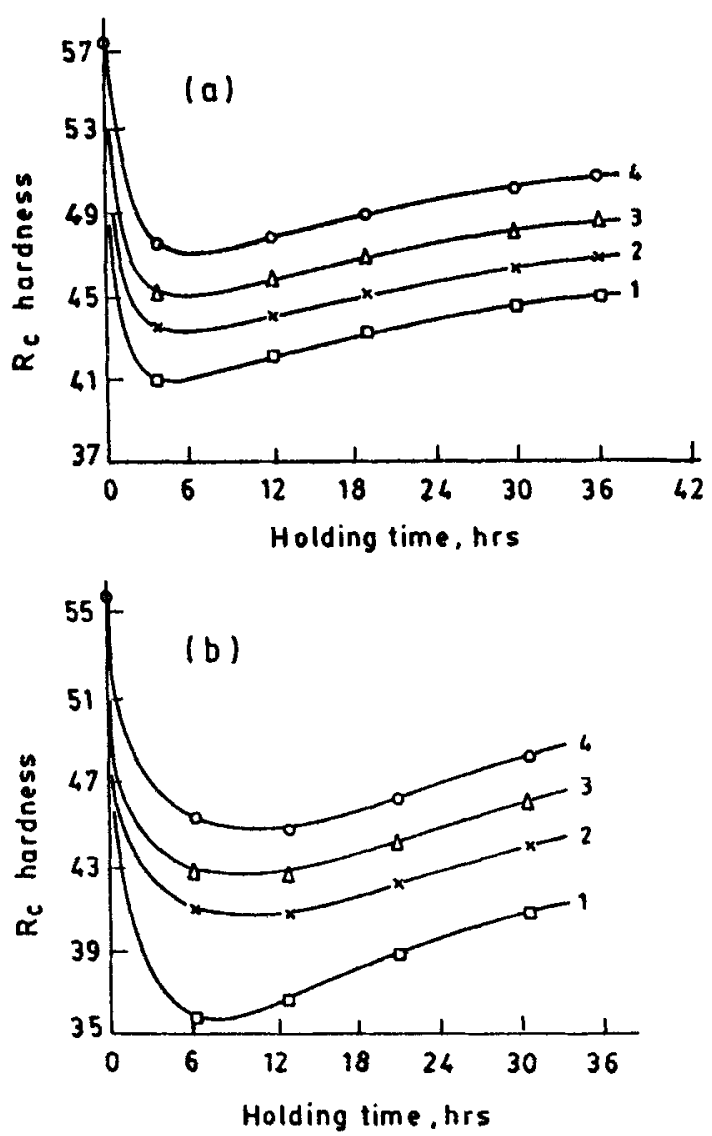

Figure 2. Influence of holding time at $1050^{\circ} \mathrm{C}$ on hardness of alloys $1-4$ (see table 1 ). 


\section{Discussion and conclusions}

The shape of the curves obtained in figure 2 shows that a transient partly graphitized state has been attained in all cases after an intermediate annealing length of time $(3-6 \mathrm{~h}$ ). Continued annealing (up to $36 \mathrm{~h}$ ) produced an opposite effect of carbidization of the partly graphitized metal.

These results were corroborated by metallography, which showed the appearance of temper carbon in the metal and then its disappearance.

The lowest hardness in the partially graphitized state was found in gravity die-cast metal of alloy 1 . With a hardness of $R_{\mathrm{c}} 36$ this metal has an acceptable level of machinability. After machining the parts can be subjected to 'carbidizing' annealing which brings the hardness to $>\boldsymbol{R}_{\mathrm{c}} \mathbf{4 0}$. Or else we can use such alloys as heat-resistant, prone to age-hardening during exploitation.

The authors have patented in the former USSR the practical applications of the phenomena described above (Silman et al 1986b).

\section{Acknowledgement}

The authors wish to thank for attention to this work Prof. P Ramachandra Rao, Director, National Metallurgical Laboratory, Jamshedpur. One of the authors (AAZ) is indebted to the Tata Iron and Steel Co., for financial assistance.

\section{References}

Silman G I, Zhukov A A and Zhavoronkov Yu V 1983 in Questions of formation of metastable structures of alloys (Ukraine: Dnepropetrovsk State University) pp. 161-172

Silman G I, Zhukov A A and Zhavoronkov Yu V 1986a in Thermodynamics of cast alloys structure formation (Kiev: Institute of Foundry Problems) pp 104-107

Silman G I, Zhukov A A, Zhavoronkov Yu V and Froltsov M S 1986b Soviet Patent No. 246346 (special series)

Zhukov A A 1971 Geometrical thermodynamics of iron alloys (Moscow: Metallurgia) pp 272

Zhukov A A 1979 Geometrical thermodynamics of iron alloys (Moscow: Metallurgia) pp 232 